\title{
Purification and in vitro antioxidant activities of tellurium-containing phycobiliproteins from tellurium-enriched Spirulina platensis
}

This article was published in the following Dove Press journal:

Drug Design, Development and Therapy

9 October 2014

Number of times this article has been viewed

\author{
Fang Yang' \\ Ka-Hing Wong ${ }^{2}$ \\ Yufeng Yang ${ }^{3}$ \\ Xiaoling $\mathrm{Li}^{\prime}$ \\ Jie Jiang ${ }^{\prime}$ \\ Wenjie Zheng' \\ Hualian Wu' \\ Tianfeng Chen' \\ 'Department of Chemistry, Jinan \\ University, Guangzhou, People's \\ Republic of China; ${ }^{2}$ Department \\ of Applied Biology and Chemical \\ Technology, The Hong Kong \\ Polytechnic University, Hong \\ Kong, People's Republic of China; \\ ${ }^{3}$ Institute of Hydrobiology, College \\ of Life Science and Technology, Jinan \\ University, Guangzhou, People's \\ Republic of China
}

\begin{abstract}
Tellurium-containing phycocyanin (Te-PC) and allophycocyanin (Te-APC), two organic tellurium (Te) species, were purified from tellurium-enriched Spirulina platensis by a fast protein liquid chromatographic method. It was found that the incorporation of Te into the peptides enhanced the antioxidant activities of both phycobiliproteins. With fractionation by ammonium sulfate precipitation and hydroxylapatite chromatography, Te-PC and Te-APC could be effectively separated with high purity, and Te concentrations were 611.1 and $625.3 \mu \mathrm{g} \mathrm{g}^{-1}$ protein in Te-PC and Te-APC, respectively. The subunits in the proteins were identified by using MALDI-TOF-TOF mass spectrometry. Te incorporation enhanced the antioxidant activities of both phycobiliproteins, as examined by 2,2 '-azino-bis(3-ethylbenzothiazoline-6-sulphonic acid assay. Moreover, Te-PC and Te-APC showed dose-dependent protection on erythrocytes against the water-soluble free radical initiator $2,2^{\prime}$-azo(2-asmidinopropane) dihydrochloride-induced hemolysis. In the hepatoprotective model, apoptotic cell death and nuclear condensation induced by tert-butyl hydroperoxide in HepG2 cells was significantly attenuated by Te-PC and Te-APC. Taken together, these results suggest that Te-PC and Te-APC are promising Te-containing proteins with application potential for treatment of diseases related to oxidative stress.
\end{abstract}

Keywords: tellurium, phycocyanin, allophycocyanin, purification, antioxidant activity

\section{Introduction}

Spirulina platensis (S. platensis), a blue-green algae, is commercially available for human consumption and used as a functional food because of its nutritional and medicinal properties. ${ }^{1-4}$ Researches have shown that $S$. platensis is a good carrier for selenium (Se) accumulation. ${ }^{5,6}$ By way of aquatic medium, S. platensis is an easily Se-supplementable vegetable. ${ }^{7}$ The accumulated Se is mainly incorporated into proteins of $S$. platensis cells, and the selenized protein exists mainly as seleno-methionine and seleno-cysteine. ${ }^{8,9}$ Moreover, it has become clear that most physiologic effects of Se are exerted by selenoproteins. ${ }^{6,9,10}$ Our previous studies showed the separation of high-purity Se-containing phycocyanin (Se-PC) and allophycocyanin (Se-APC) from Se-enriched $S$. platensis. ${ }^{7,8,11}$ Our research also indicated that purified Se-PC was a promising organic Se species with potential applications in cancer chemoprevention, and both Se-PC and Se-APC are promising organic Se species with potential applications in antioxidant therapy on human erythrocytes and hepatoprotective activities. $^{7,11,12}$

Tellurium (Te) is in the same group as sulfur and Se in the periodic table and is classified as a metalloid. The similarity of Se and Te encompasses not only their names and positions on the periodic table, but to a large degree their chemical and biochemical 
properties. ${ }^{13,14}$ Se was found to be an essential element in the mid-1950s after being regarded as a toxic element for a long time. ${ }^{13,15}$ Currently, we know Se plays an important role in therapies for many diseases such as cancer, human immunodeficiency virus/acquired immunodeficiency syndrome, and aging. ${ }^{10,13,15}$ In contrast, Te is a rare but non-essential trace element. ${ }^{16}$ However, studies have found that the typical amounts of Te in the human body are larger than $0.5 \mathrm{~g}$, which exceeds the levels of all other trace elements in humans. ${ }^{17}$ Although thought to be toxic, the toxicity of Te depends on the chemical form and the quantity of the element consumed. Te poisoning is characterized by nausea, somnolence, and garlic odor on the breath and in urine caused by dimethyl telluride. ${ }^{17}$ Te can also interfere with cholesterol synthesis by blocking the cytochrome P450 reductase-linked terminal oxidase. ${ }^{18}$ Toxicity of Te on the nervous system is suggestive of peripheral neuropathy during a period of active myelinogenesis through alteration of the transcription of the myelin proteins. ${ }^{19}$ Widy-Tyszkiewicz et $\mathrm{al}^{20}$ found that Te induced cognitive deficits in rats, similar to neuropathological changes in the central nervous system. Santos et $\mathrm{al}^{21}$ also demonstrated the hemolytic and genotoxic evaluation of organochalcogens in human blood cells in vitro. Recently, Roy and Hardej ${ }^{22}$ found that Te tetrachloride and diphenyl ditelluride caused cytotoxicity in rat hippocampal astrocytes through induction of an intrinsic apoptotic pathway. However, the toxicity of Te has received less attention than that of Se, which may be due to the less frequent contact of humans with this element and its compounds. ${ }^{17}$

In the last few decades, increasing attention has been paid to the investigation of Te compounds as therapeutic agents. ${ }^{23}$ There are two main types of Te compounds, inorganic Te and organic Te derivatives, which have been found to show antimicrobial, antihelmintic, antioxidant, immunomodulatory, and anticancer activities. ${ }^{17,23-30}$ For instance, organic Te compounds were also identified as potent inhibitors of cysteine proteases, indicating their promising application potential as antimetastatic agents. ${ }^{29}$ RT-04, a novel organotellurium(IV) compound, was able to induce apoptosis in HL60 human promyelocytic leukemia cells by down-modulation of Bcl-2 expression. ${ }^{28}$ Moreover, an organotelluroxetane, RF-07, displayed significant protective effect on pilocarpine-induced status epilepticus, indicating its promising therapeutic potential as an antiepileptogenic agent. ${ }^{30}$ Many studies also found that small inorganic Te complexes, ammonium trichloro (dioxoethylene-O,O') tellurate (AS101) and Octa-O-bis-(R,R)-tartarate ditellurane (SAS), displayed excellent safety profiles and promising anti-cancer therapeutic potentials. ${ }^{17}$ Therefore, just like Se 50 years ago, it is possible that the toxic element Te will ultimately be found to be an essential element. ${ }^{14}$

Compared to the numerous studies of Se-containing proteins, such as Se-PC and Se-APC,,$^{8,11,12,31-35}$ limited information on the chemical and biological properties of Te-containing proteins is available. Considering the biological similarity of Se and Te, some interesting and significant results might be attained. Thus, the objective of this study is to present a simple and efficient way to separate Te-PC and Te-APC from Te-enriched $S$. platensis, and investigate the in vitro antioxidant activities of both phycobiliproteins. The obtained results confirmed the incorporation of Te into PC and APC, which caused no difference in identification of the subunits by MALDI-TOF-TOF. Most importantly, Te incorporation enhanced the antioxidant activities of both phycobiliproteins. Taken together, these results suggest that Te-PC and Te-APC are novel organic Te species with application potential in antioxidation, and deserve further development for treatment of diseases related to oxidative stress in the future.

\section{Materials and methods}

\section{Cultivation of high Te-enriched S. platensis}

$S$. platensis was provided by the Research Center of Hydrobiology of Jinan University (Guangzhou, People's Republic of China). All cultivations were conducted in $500 \mathrm{~mL}$ Erlenmeyer flasks containing $250 \mathrm{~mL}$ Zarrouk medium $(\mathrm{pH} 8.5)$ at $30^{\circ} \mathrm{C} \pm 1^{\circ} \mathrm{C}$ with a light illumination of $4,000 \mathrm{~lx}$ and a 14:10 hour light:dark cycle. Te was added in the form of sodium tellurite $\left(\mathrm{Na}_{2} \mathrm{TeO}_{3}\right)$ stepwise to obtain different final concentrations, as described in Table 1. S. platensis was harvested and freeze dried on day 11 . The dry weight of algal biomass was determined by drying the $S$. platensis at $70^{\circ} \mathrm{C}$ in a vacuum oven until a constant weight was obtained.

\section{Purification of Te-PC and Te-APC}

The freeze dried Te-enriched $S$. platensis cells were suspended in $1 \mathrm{mM}$ Na-phosphate buffer (pH 6.8). The cell suspension was frozen (at $-20^{\circ} \mathrm{C}$ ) and thawed (at $4^{\circ} \mathrm{C}$ ) ten

Table I Stepwise addition time and concentration of $\mathrm{Te}$ in Spirulina platensis and the final biomass of S. platensis

\begin{tabular}{lllll}
\hline $\begin{array}{l}\text { Day } \mathbf{7} \\
\left(\mathbf{m g ~ L}^{-1}\right)\end{array}$ & $\begin{array}{l}\text { Day 8 } \\
\left(\mathbf{m g ~ L}^{-1}\right)\end{array}$ & $\begin{array}{l}\text { Day 9 } \\
\left(\mathbf{m g ~ L}^{-1}\right)\end{array}$ & $\begin{array}{l}\text { Final Te } \\
\text { concentration } \\
\left(\mathbf{m g ~ L}^{-1}\right)\end{array}$ & $\begin{array}{l}\text { Final biomass } \\
\text { of S. platensis } \\
\left(\mathbf{g ~ L}^{-1}\right)\end{array}$ \\
\hline 200 & 250 & 250 & 700 & $1.20 \pm 0.03$ \\
200 & 300 & 300 & 800 & $1.21 \pm 0.02$ \\
250 & 300 & 350 & 900 & $1.23 \pm 0.05$ \\
250 & 350 & 400 & 1,000 & $1.11 \pm 0.04$ \\
\hline
\end{tabular}

Abbreviation: Te, tellurium. 
times and was then sonicated for 10 minutes (using a Sonics VCX 600 system, $200 \mathrm{~W})$. Next, the sonicated cells were centrifuged at $10,000 \times g$ (using a Millipore microcentrifuge; EMD Millipore, Billerica, MA, USA) for 60 minutes to collect the Te-PC and Te-APC containing supernatant for further purification.

The above supernatant was fractionated by precipitation with ammonium sulfate at $30 \%$ saturation, followed by $65 \%$ saturation. The precipitate obtained from $30 \%$ saturation of ammonium sulfate was discarded, and the supernatant was further brought to $65 \%$ saturation of ammonium sulfate. The collected precipitate from $65 \%$ saturation of ammonium sulfate was redissolved in $5 \mathrm{~mL} \mathrm{Na-phosphate} \mathrm{buffer}$ ( $1 \mathrm{mM}, \mathrm{pH} 6.8$ ) and dialyzed overnight at $4^{\circ} \mathrm{C}$ against the same buffer. Then, the supernatant proteins containing mainly Te-PC and Te-APC were collected by centrifugation at $10,000 \times g$ (using an EMD Millipore microcentrifuge) for 60 minutes at $4^{\circ} \mathrm{C}$.

Next, the above supernatant was applied to a Bio-Logic DuoFlow chromatography system equipped with a Bio-Rad Econo-column $(1.5 \times 30 \mathrm{~cm})$ packed with hydroxyapatite (HA). The column was developed with six different concentration gradients of Na-phosphate buffer with $0.2 \mathrm{M}$ $\mathrm{NaCl}$ (pH 6.8): namely, 0.001, 0.005, 0.01, 0.02, 0.05, and $0.10 \mathrm{M}$. The flow rate was $0.5 \mathrm{~mL} / \mathrm{min}$, and the effluent was collected in $2 \mathrm{~mL}$ fractions. All fractions having a purity ratio of absorbance $(\mathrm{A})_{620} / \mathrm{A}_{280}>4.5$ and $\mathrm{A}_{650} / \mathrm{A}_{280}>2.5$ were pooled, and they possessed a high purity of Te-PC and TeAPC, respectively.

Te-APC was purified for the second time to obtain higher purity with the same HA chromatography system. This time, the column was developed with four different concentration gradients of Na-phosphate buffer with $0.2 \mathrm{M} \mathrm{NaCl}$ (pH 6.8): that is, $0.005,0.02,0.05$, and $0.10 \mathrm{M}$. All fractions having a purity ratio of $\mathrm{A}_{650} / \mathrm{A}_{280}>5.0$ were pooled, which contributed to the high purity of Te-APC. The purification procedures for PC and APC from S. platensis were the same as that for Te-PC and Te-APC from Te-enriched S. platensis, as described previously in this section.

\section{Spectroscopic measurements}

All spectra were recorded at room temperature. Ultravioletvisible (UV-VIS) absorption spectra were measured on a CARY 500 spectrophotometer between 250 and $700 \mathrm{~nm}$, with a $1 \mathrm{~cm}$ path length. Purity ratio $\left(\mathrm{A}_{618} / \mathrm{A}_{280}\right.$ and $\left.\mathrm{A}_{652} / \mathrm{A}_{280}\right)$ was calculated based on the UV-VIS spectra. The fluorescence emission spectra were recorded on a F4500 Fluorescence spectrometer (Hitachi Ltd., Tokyo, Japan).

\section{Sodium dodecyl sulfate polyacrylamide gel electrophoresis analysis}

Sodium dodecyl sulfate polyacrylamide gel electrophoresis (SDS-PAGE) on $15 \%$ polyacrylamide gel was carried out using the Laemmli buffer system. Each protein sample was mixed with an equal volume of sample buffer containing $2 \%$ (w/v) SDS, 10\% (v/v) glycerol, 5\% (v/v) 2-mercaptoethanol, $0.002 \%(\mathrm{w} / \mathrm{v}$ ) bromophenol blue, and $60 \mathrm{mM}$ Tris (pH 6.8), and boiled for 10 minutes. At room temperature, electrophoresis was carried out, and the gel was stained with colloidal coomassie blue.

\section{In-gel digestion}

Protein gel bands, carefully excised from colloidal coomassie blue stained gels, were excised on extremely clean surfaces and cut into small pieces with a surgical needle. Then, the in-gel digestion was done according to the following protocol. Gel pieces were destained with $100 \mathrm{mM}$ $\mathrm{NH}_{4} \mathrm{HCO}_{3}$ in $50 \%$ methanol (v/v) three times. Then, the gel pieces were dehydrated with acetonitrile $(\mathrm{ACN})$ and dried by speed vacuum (SAVANT ${ }^{\text {TM }}$ refrigerated condensation trap system). The dried gel samples were incubated in a trypsin solution containing $50 \mathrm{mM} \mathrm{NH}_{4} \mathrm{HCO}_{3}$ and $40 \mu \mathrm{g} / \mu \mathrm{L}$ trypsin for 30 minutes on ice. After addition of a buffer solution ( $25 \mathrm{mM} \mathrm{NH}_{4} \mathrm{HCO}_{3}$ ) to cover all gel pieces, the gel samples were incubated at $32^{\circ} \mathrm{C}$ overnight. Next, the digested peptides were extracted from the gel pieces with buffer solution and washing solution (ACN containing 5\% trifluoroacetic acid [TFA]) by sonication for 10 minutes (Branson 5210 system). The extraction was repeated twice. There were three extractions in total. Finally, the supernatant containing the digested peptides was dried down using a speed vacuum.

\section{Peptide mass fingerprint analysis by MALDI-TOF-TOF mass spectrometry and database searching}

The digested peptide samples were dissolved in $0.1 \%$ TFA and applied to a Zip Tip u- $\mathrm{C}_{18}$ column (EMD Millipore) for desalting. Then, the desalted peptide samples were redissolved in $50 \%$ ACN containing $0.1 \%$ TFA and were added onto a 192-well MALDI plate and air-dried prior to analysis in the MALDI-TOF-TOF system. The $\alpha$ and $\beta$ subunit fractions of Te-PC and Te-APC collected from SDS-PAGE were dried by speed vacuum prior to trypsin digestion. The digested subunit samples were directly added onto the 192-well MALDI plates for analysis. MALDI-TOF-TOF analysis was performed using an ABI Applied Biosystems 
4700 Proteomics Analyzer (GE Healthcare UK Ltd., Little Chalfont, UK). Mass spectra were obtained using a laser (337 nm, $200 \mathrm{~Hz}$ ) as a desorption ionization source. Data were acquired in the reflection positive mode using delayed extraction. Spectra were calibrated using trypsin autolysis products (m/z 842.51 and 2,211.10) as internal standards. After mass spectrometry (MS) acquisition, the ten strongest peptides per spot were selected automatically for tandem MS analysis. Identification of proteins was performed by searching against the National Center for Biotechnology Information (NCBI, Bethesda, MD, USA) non-redundant protein sequence database. The peptide mass tolerance was set as $0.5 \mathrm{Da}$ (50 ppm), and variable modifications of oxidation and carbamidomethylation were considered. Automatic data analysis and database searching were carried out by the GPS Explore software (Thermo Fisher Scientific, Waltham, MA, USA). The probability score generated was used as criterion for identification. Proteins with total score $>59$ or best ion score $>29$ were considered to be credible.

\section{Determination of total Te, inorganic Te, and organic Te concentrations}

Te concentration was determined by inductively coupled plasma atomic emission spectroscopy (ICP-AES; PerkinElmer Inc., Waltham, MA, USA) method, as previously described. ${ }^{8}$ Briefly, the sample was digested with $3 \mathrm{~mL}$ concentrated nitric acid and $1 \mathrm{~mL} \mathrm{H}_{2} \mathrm{O}_{2}$ in a digestive stove (Shanghai Qian Jian Instruments Co, Ltd., Shanghai, People's Republic of China) at $180^{\circ} \mathrm{C}$ for 3 hours. Then, the digested product was reconstituted to $10 \mathrm{~mL}$ with Milli-Q $\mathrm{H}_{2} \mathrm{O}$ and used for total Te determination. To determine inorganic Te concentration, the dried algal samples were extracted with $15 \% \mathrm{HCl}$; then, the extract was analyzed by ICP-AES directly. Organic Te concentration was calculated as the difference between the total Te concentration and the inorganic Te concentration.

\section{Trolox equivalent antioxidant capacity assay}

ABTS $\bullet^{+}$free radical scavenging activities of antioxidants were measured as follows. The 2,2'-azino-bis(3ethylbenzothiazoline-6-sulphonic acid (ABTS) reagent was prepared by passing the ABTS stock solution $(5 \mathrm{mM})$ through manganese dioxide to allow the completion of radical generation; then, the solution was passed through a $0.2 \mu \mathrm{M}$ polyvinyl difluoride (PVDF) syringe filter. After that, the filtrate was diluted with $5 \mathrm{mM}$ phosphate-buffered saline (PBS) buffer ( $\mathrm{pH} 7.4$ ) to an absorbance of $0.70 \pm 0.02$ at $734 \mathrm{~nm}$, as recorded on a spectrophotometer (Genesys 5; Spectronic Instruments,
Inc., Rochester, NY, USA). To determine the antioxidant activity, $1 \mathrm{~mL}$ of ABTS reagent was mixed with $50 \mu \mathrm{L}$ of sample or positive control. The absorbance was then measured at $734 \mathrm{~nm}, 6$ minutes after the initiation of mixing.

\section{Erythrocyte hemolysis assay}

The AAPH (2,2'-azobis[2-amidinopropane]dihydrochloride) free radical scavenging activities of antioxidants were measured as the inhibition of erythrocyte hemolysis, as per our previous study. ${ }^{7}$

\section{Cell culture and determination of cell viability}

HepG2 human hepatocarcinoma cell line was obtained from the American Type Culture Collection (ATCC, Manassas, VA, USA). The cells were grown in Dulbecco's Modified Eagle's Medium (DMEM) supplemented with fetal bovine serum $(10 \%)$, penicillin $(100 \mathrm{IU} / \mathrm{mL})$, and streptomycin (50 units $/ \mathrm{mL}$ ) at $37^{\circ} \mathrm{C}$ in a humidified incubator with $5 \% \mathrm{CO}_{2}$ atmosphere. Cell viability was determined by measuring the ability of the cells to metabolize 3-[4,5-dimethylthiazol-2-yl]-2,5-diphenyltetrazolium bromide (MTT) to a purple formazan dye, as previously described. ${ }^{7}$

\section{Flow cytometric analysis}

Flow cytometric analysis was carried out according to our previous study. ${ }^{36}$ Briefly, HepG2 cells after treatments were harvested by centrifugation and washed with PBS. Cells were stained with propidium iodide (Sigma-Aldrich Co., St Louis, MO, USA) after fixation with $70 \%$ ethanol at $-20^{\circ} \mathrm{C}$ overnight. Labeled cells were washed with PBS and then analyzed by flow cytometer. The cell cycle distribution was analyzed using MultiCycle software (Phoenix Flow Systems, San Diego, CA, USA). The proportions of cells in gap 0/gap 1 (G1), synthesis, and gap 2/mitosis phases were represented as deoxyribonucleic acid (DNA) histograms. Apoptotic cells with hypodiploid DNA contents were measured by quantifying the sub-G1 peak. For each experiment, 10,000 events per sample were recorded.

\section{4',6-diamidino-2-phenylindole staining}

Nuclear staining was examined by fluorescence staining using DAPI (4',6-diamidino-2-phenylindole; Sigma-Aldrich) as a molecular probe. Briefly, cells cultured in chamber slides were fixed with $3.7 \%$ formaldehyde and permeabilized with $0.1 \%$ Triton X-100 in PBS. Cells were incubated with $1 \mu \mathrm{g} / \mathrm{mL}$ DAPI for 15 minutes at $37^{\circ} \mathrm{C}$. After that, cells were washed with PBS and examined with a fluorescence 
microscope (Nikon Eclipse 80i, magnification 200×; Nikon Corporation, Tokyo, Japan).

\section{Statistical analysis}

Data were expressed as mean \pm standard deviation (SD) from at least three independent experiments. The difference between two groups was analyzed by two-tailed Student's $t$-test, and the significance among three or more groups was analyzed by one-way analysis of variance (ANOVA) multiple comparisons. In all analyses, a value of $P<0.05$ was considered statistically significant.

\section{Results and discussion}

\section{Accumulation and transformation of tellurite in S. platensis, and the effects on the biomass concentration}

Our previous studies have showed that $S$. platensis is a good carrier for Se. ${ }^{5}$ In the preliminary screening of the current study, we have tested the tolerance of $S$. platensis to tellurite for a wide range of concentrations from 0 to $1,000 \mathrm{mg} / \mathrm{L}$. The results showed that $S$. platensis was resistant to tellurite. This study aimed to purify Te-containing proteins from the microalgae. Therefore, we chose the higher concentrations of tellurite for Te accumulation with the purpose of obtaining higher Te-containing proteins. As shown in Figure 1, we demonstrated that tellurite could be efficiently accumulated in S. platensis during cultivation, and inside the cells tellurite was transformed to organic Te at a high ratio. The percentage of organic Te in S. platensis was 81.3, 76.1, 82.6, and 76.8\%, under different Te concentrations in the culture medium. Even at a high tellurite concentration of $1,000 \mathrm{mg} \mathrm{L}^{-1}$, S. platensis could still transform tellurite to organic Te. In order to investigate whether the tellurite accumulation and biotransformation

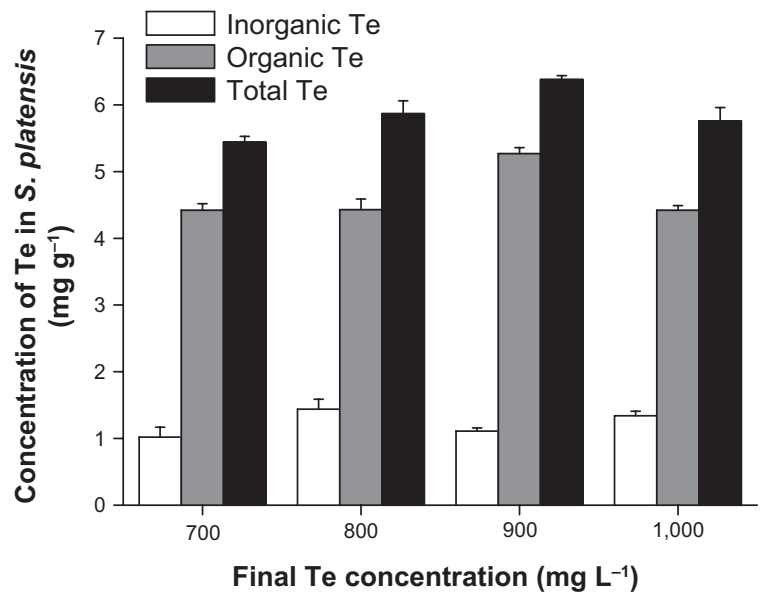

Figure I Accumulation of tellerium (Te) in Spirulina platensis cultured with different concentrations of Te. would significantly $(P<0.05)$ affect the growth of $S$. platensis, we monitored the changes in the final biomass after Te addition (Table 1). The results showed that the final biomass of S. platensis increased by $3.46 \%, 4.76 \%$, and $6.06 \%$ under the final tellurite concentrations of 700 , 800 , and $900 \mathrm{mg} \mathrm{L}^{-1}$, respectively. The highest final tellurite concentration $\left(1,000 \mathrm{mg} \mathrm{L}^{-1}\right)$ resulted in the lowest biomass concentration (3.90\% less than that of the control), possibly due to the toxic effect of high Te stress. Therefore, just like Se, tellurite also had either stimulating or toxic effects on $S$. platensis, depending on the tellurite level. Interestingly, during the experiments, strong garlic-like odors could be smelled. This information further confirmed the transformation of tellurite into volatile Te products by $S$. platensis cells, which might mitigate the toxicity of tellurite. ${ }^{13}$ As a result, $S$. platensis possessed tolerance to high levels of tellurite, and it was a good carrier for tellurite accumulation.

\section{Purification of Te-PC and Te-APC, and determination of Te concentration}

Te-enriched $S$. platensis has been obtained by adding tellurite into $S$. platensis. Considering the percentage of organic Te in $S$. platensis and the toxicity of tellurite, we used the final tellurite concentration of $700 \mathrm{mg} \mathrm{L}^{-1}$ to acquire Te-enriched S. platensis, from which Te-PC and Te-APC were purified (Figure 2, Table 2 and 3).

Phycocyanin (PC), a natural blue dye with many commercial uses, is the major soluble protein extracted from cyanobacteria such as $S$. platensis. ${ }^{8,37}$ Allophycocyanin (APC) is the minor soluble protein component of $S$. platensis cell extract. To separate Te-PC and Te-APC, we applied a twostep precipitation procedure with ammonium sulfate at $30 \%$ and $65 \%$ saturation. The initial $30 \%$ saturation of ammonium sulfate removed contaminating proteins, and the next $65 \%$ saturation of ammonium sulfate precipitated both the Te-PC and Te-APC crude fractions, which were then subjected to HA chromatography. The elution involved six different concentration gradients of $0.001,0.005,0.01,0.02,0.05$, and $0.10 \mathrm{M}$ Na-phosphate buffer with $0.2 \mathrm{M} \mathrm{NaCl}(\mathrm{pH} \mathrm{6.8)}$. From this step, a good separation of Te-PC from Te-APC was achieved (Figure 2A). Te-PC and Te-APC were eluted in the fourth and sixth concentration gradients of 0.02 and $0.10 \mathrm{M}$, respectively. The purity ratio $\left(\mathrm{A}_{618} / \mathrm{A}_{280}\right)$ of Te-PC was up to 5.59, and the purity ratio $\left(\mathrm{A}_{652} / \mathrm{A}_{280}\right)$ of Te-APC was 3.11 . Therefore, both the two-step precipitation and the six different concentration gradients elution procedure contributed to the efficient separation of contaminating protein and Te-PC from Te-APC. 
A

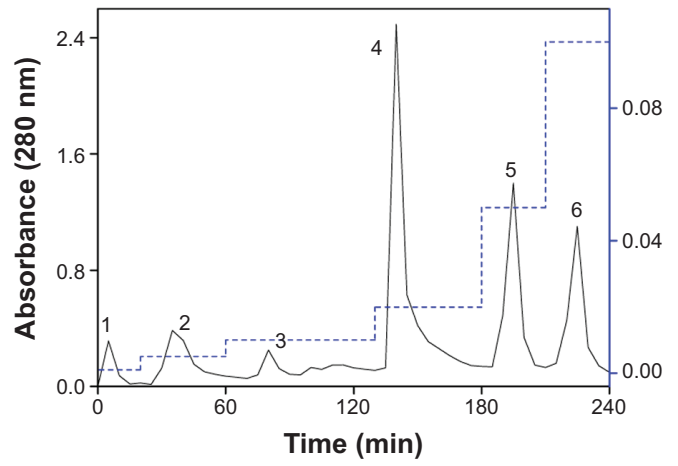

B

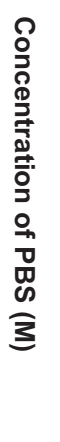

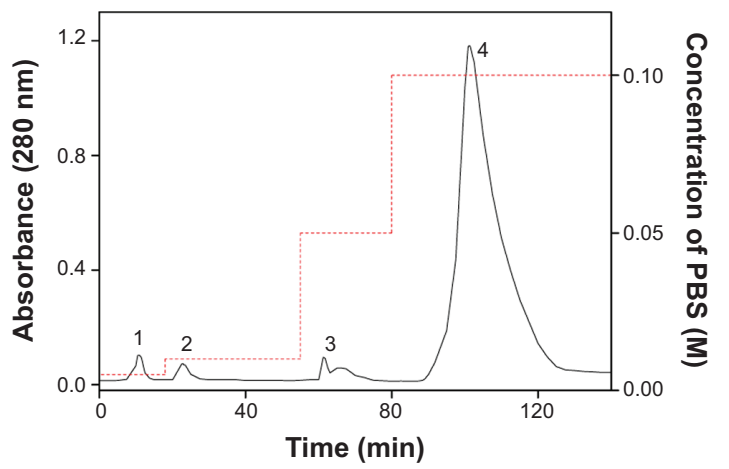

Figure 2 HA chromatography of Te-PC and Te-APC.

Notes: (A) Elution process of the first HA chromatography. The sample was eluted with different PBS concentration gradients: first at 0.00 IM, followed by $0.005 \mathrm{M}, 0.0 \mathrm{I}$ M, $0.020 \mathrm{M}, 0.05 \mathrm{M}$, and last at $0.10 \mathrm{M}$. The flow rate was $0.5 \mathrm{~mL} \mathrm{~min}{ }^{-1}$. (B) Elution process of the second HA chromatography. The sample was eluted with different PBS concentration gradients: first at $0.005,0.02 \mathrm{M}$; followed by $0.05 \mathrm{M}$; and last at $0.10 \mathrm{M}$. The flow rate was $0.5 \mathrm{~mL} \mathrm{~min}^{-1}$.

Abbreviations: Min, minutes; PBS, phosphate-buffered saline; HA, hydroxyapatite; Te-PC, tellurium-containing phycocyanin; Te-APC, tellurium-containing allophycocyanin.

Further purification of Te-APC was achieved by the second application of HA chromatography (Figure 2B). The purity ratio was enhanced from 3.11 to 5.16. As compared with other published purification methods, ${ }^{38}$ our method was more convenient and efficient, with good purity performance.

Our previous research ${ }^{5}$ indicated that under photoautotrophic culture conditions, the organic Se in S. platensis accounted for about $80 \%$ of the total Se accumulated in the algal cells and was comprised of about $60 \%$ of the water-soluble protein-bound form. Organic Te demonstrated similar characterization in S. platensis, accounting for $50 \%$ of the water-soluble protein-bound form. We obtained the Te concentration of $611.1 \mu \mathrm{g} \mathrm{g}^{-1}$ in the Te-PC after HA chromatography once, and the Te concentration of $625.3 \mu \mathrm{g} \mathrm{g}^{-1}$ in the Te-APC after HA chromatography twice. Further confirmation for Te-PC and Te-APC was then performed, as described in the "Characterization of Te-PC and Te-APC by UV-VIS and fluorescence spectroscopy" section.

\section{Characterization of Te-PC and Te-APC by UV-VIS and fluorescence spectroscopy}

The standard analytical methods for characterization of PC and APC are UV-VIS spectroscopy, fluorescence spectroscopy, and SDS-PAGE of the denatured proteins. ${ }^{39-41}$

Table 2 Purity ratio and Te concentration of Te-PC obtained in different purification steps

\begin{tabular}{lll}
\hline Purification step & $\begin{array}{l}\text { Purity ratio } \\
\left(\mathbf{A}_{618} / \mathbf{A}_{280}\right)\end{array}$ & $\begin{array}{l}\text { Te concentration } \\
\left(\mu \mathrm{g} \mathrm{g}^{-1} \text { protein }\right)\end{array}$ \\
\hline Crude extract & 0.31 & 372.0 \\
$\begin{array}{l}\text { Precipitation with } 30 \% \\
\text { saturation of }\left(\mathrm{NH}_{4}\right)_{2} \mathrm{SO}_{4}\end{array}$ & 0.41 & 405.5 \\
$\mathrm{HA}$ chromatography & 5.59 & \\
\hline
\end{tabular}

Abbreviations: Te-PC, tellurium-containing phycocyanin; HA, hydroxyapatite; Te, tellerium.
As shown in Figure 3A, the characteristic absorption peak at $618 \mathrm{~nm}$ and strong absorbance below $300 \mathrm{~nm}$ in the UV-VIS spectrum of Te-PC verified the presence of the Te-PC. The fluorescence spectrum of Te-PC showed maximum emission at $646 \mathrm{~nm}$ (Figure 3C), which was in accordance with the spectral property of PC reported in the literature. ${ }^{8,38,39}$

Te-APC was corroborated by the characteristic absorption peak at $652 \mathrm{~nm}$, a shoulder at $620 \mathrm{~nm}$, and strong absorbance at $280 \mathrm{~nm}$ in the UV-VIS spectra (Figure 3B). The decrease in relative intensity of peaks at $280 \mathrm{~nm}$ and $620 \mathrm{~nm}$ indicated the successive improvement in the purity of TeAPC in terms of purity ratio $\left(\mathrm{A}_{652} / \mathrm{A}_{280}\right)$. The fluorescence spectrum of purified Te-APC showed maximum emission at $660 \mathrm{~nm}$ (Figure 3D), which was in agreement with the spectral property of APC reported in the literature.$^{39-41}$ Moreover, the lack of fluorescence emission around $646 \mathrm{~nm}$ indicated the efficient separation of Te-APC from Te-PC. From the above results, we found that Te-PC and $\mathrm{PC}$ exhibited similar spectra, the same as Te-APC and APC. It could be concluded that the incorporation of Te into PC and APC had no effect on the spectral properties of these proteins.

Table 3 Purity ratio and Te concentration of Te-APC obtained in different purification steps

\begin{tabular}{lll}
\hline Purification step & $\begin{array}{l}\text { Purity ratio } \\
\left(\mathbf{A}_{652} / \mathbf{A}_{\mathbf{2 8 0}}\right)\end{array}$ & $\begin{array}{l}\text { Te concentration } \\
\left(\mu \mathrm{g} \mathrm{g}^{-1} \text { protein }\right)\end{array}$ \\
\hline $\begin{array}{l}\text { Crude extract } \\
\text { Precipitation with } 30 \%\end{array}$ & 0.22 & 372.0 \\
$\begin{array}{l}\text { saturation of }\left(\mathrm{NH}_{4}\right)_{2} \mathrm{SO}_{4} \\
\begin{array}{l}\text { The first } \mathrm{HA} \\
\text { chromatography }\end{array}\end{array}$ & 0.23 & 405.5 \\
$\begin{array}{l}\text { The second HA } \\
\text { chromatography }\end{array}$ & 3.11 & 603.2 \\
\hline
\end{tabular}

Abbreviations: Te-APC, tellurium-containing allophycocyanin; HA, hydroxyapatite; Te, tellerium. 
A

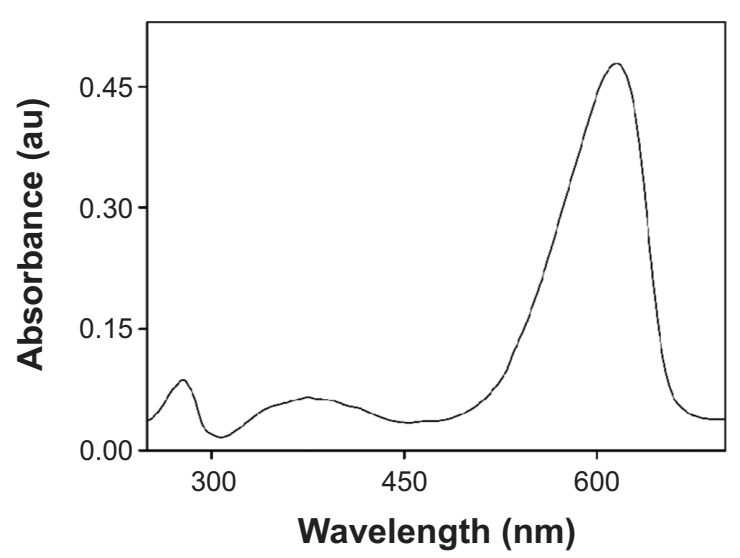

C

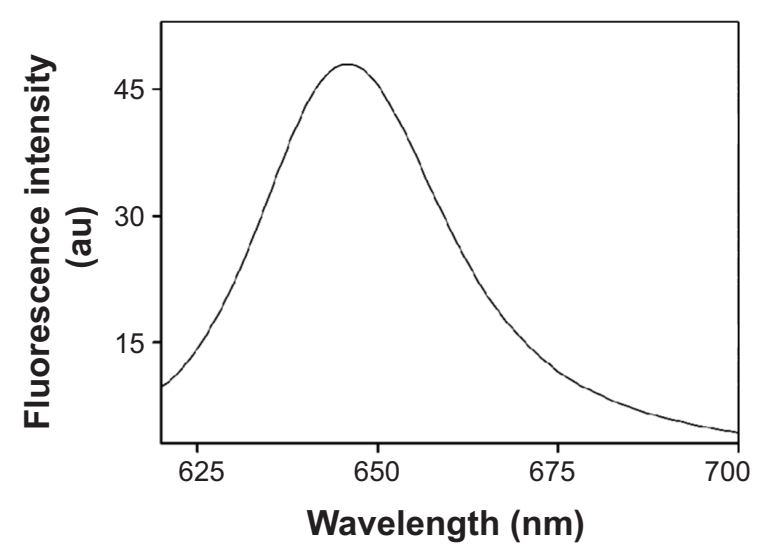

B

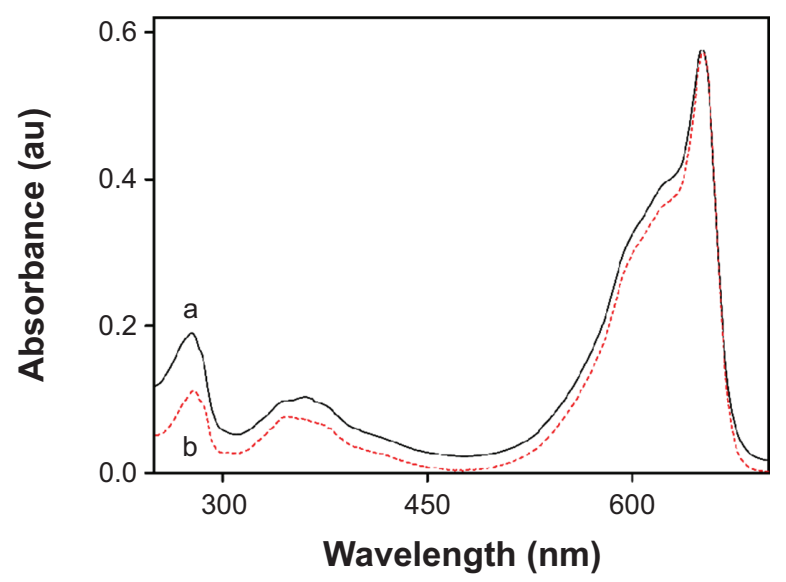

D

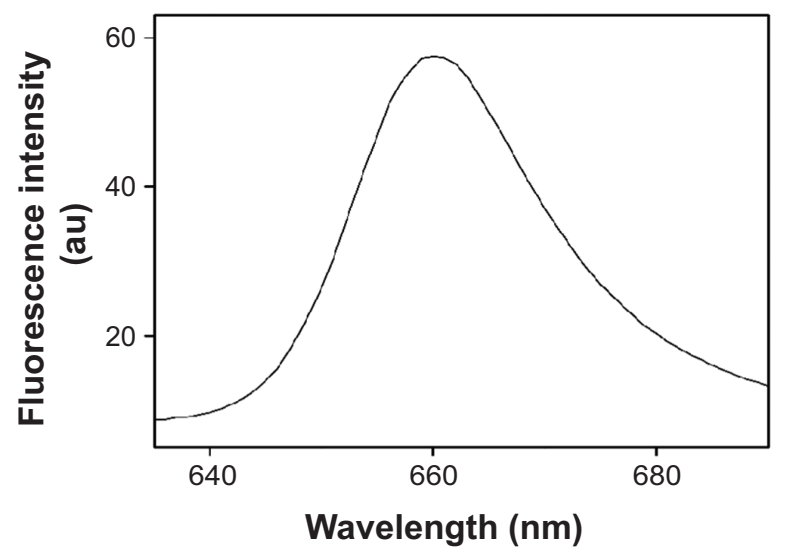

Figure 3 Spectroscopic characterization of Te-PC and Te-APC.

Notes: (A) UV-VIS spectra of Te-PC obtained from the first HA chromatography; (B) UV-VIS spectra of Te-APC obtained in different steps of purification. Line (a), pooled fractions obtained from the first HA chromatography; line (b), pooled fractions obtained from the second HA chromatography. (C) Emission spectrum of Te-PC (Ex =6I8 nm). (D) Emission spectrum of Te-APC obtained from the second HA chromatography (Ex $=652 \mathrm{~nm})$. The spectra were recorded in PBS buffer (0.5 M, pH 6.8) and normalized. Abbreviations: Te-PC, tellurium-containing phycocyanin; Te-APC, tellurium-containing allophycocyanin; UV-VIS, ultraviolet-visible; HA, hydroxyapatite; PBS, phosphatebuffered saline; Ex, excitation wavelength.

\section{SDS-PAGE and identification of $\alpha$ and $\beta$ subunits by peptide mass fingerprint}

SDS-PAGE analysis indicated two major bands corresponding to $\alpha$ and $\beta$ subunits of both Te-PC and Te-APC (Figure 4A). For Te-PC, the molecular masses of $\alpha$ and $\beta$ subunits were estimated to be $17.6 \mathrm{kDa}$ and $18.1 \mathrm{kDa}$, respectively (Figure 4B); thus, the molecular mass of the Te-PC monomer $(\alpha, \beta)$ was calculated to be $35.7 \mathrm{kDa}$. For Te-APC, molecular masses of $\alpha$ and $\beta$ subunits were $17.1 \mathrm{kDa}$ and $18.4 \mathrm{kDa}$, respectively (Figure 4C), and the molecular mass of the Te-APC monomer $(\alpha, \beta)$ was $35.5 \mathrm{kDa}$.

In order to identify $\alpha$ and $\beta$ subunits separated by SDS-PAGE, peptide mass fingerprinting (PMF) by using MALDI-TOF-TOF mass spectrometry was employed in the present study. The introduction of the Zip Tip column for desalting the digested protein samples, and the application of sonication to facilitate extraction of the peptides resulted in superior performance of the subsequent PMF analysis. Table 4 shows the accession numbers, protein molecular masses, the number of peptides identified in each subunit, and the protein score of each PMF analysis. The protein bands excised from the SDS-PAGE gel of purified PC, Te-PC, APC, and Te-APC were well identified by MALDI-TOFTOF, which confirmed the effectiveness of this fast protein liquid chromatographic system to purify Te-PC and Te-APC from $S$. platensis. Taken together, the results from UV-VIS, fluorescence spectroscopy, SDS-PAGE, and PMF analyses fully supported the successful incorporation of Te into PC and APC, and there was no change in the structures of PC and APC. Furthermore, it was observed that the incorporation of Te into PC and APC caused no difference in identification of the subunits by MALDI-TOF-TOF. 

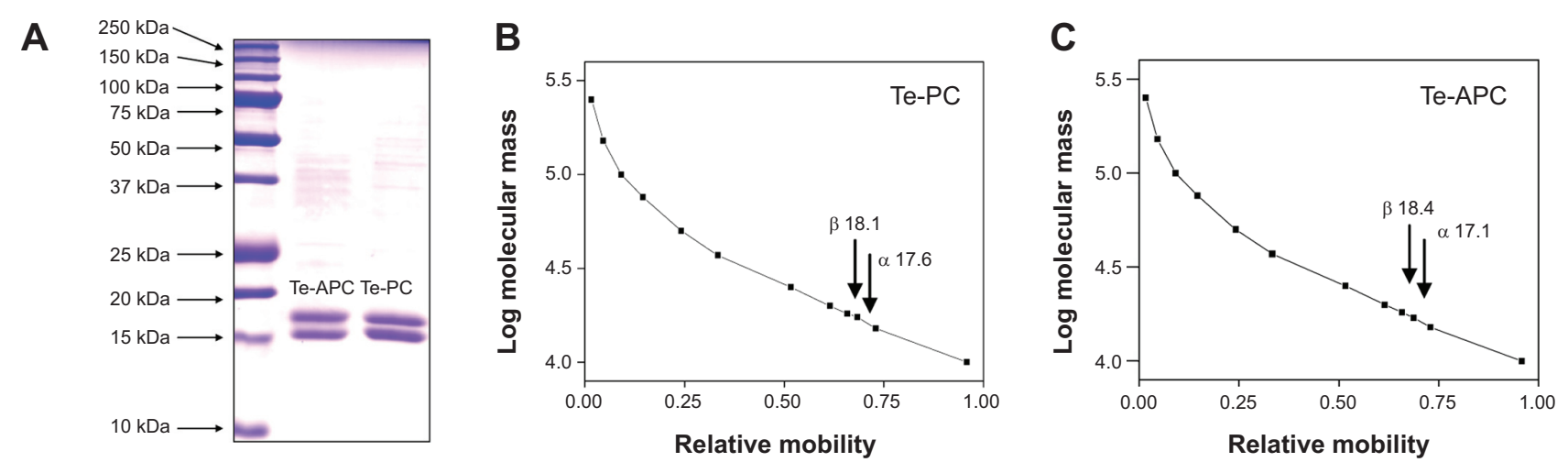

Figure 4 SDS-PAGE and identification of $\alpha$ and $\beta$ subunits by peptide mass fingerprint.

Notes: (A) SDS-PAGE analysis; and (B) the calculated molecular masses of purified Te-PC and (C) Te-APC.

Abbreviations: Te-PC, tellurium-containing phycocyanin; Te-APC, tellurium-containing allophycocyanin; SDS-PAGE, sodium dodecyl sulfate polyacrylamide gel electrophoresis.

\section{Antioxidant activities of Te-PC and Te-APC}

In a free radical scavenging assay, the relatively long-lived

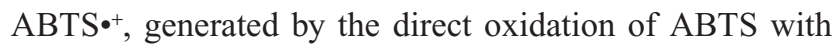
manganese dioxide, is decolorized during the reaction with hydrogen-donating antioxidants. ${ }^{42}$ This assay provides a direct comparison of the antioxidant activities of tested samples as expressed in terms of percentage inhibition. Te-PC, PC, Te-APC, and APC (Figure 5) all inhibited the formation of ABTS free radicals in a concentration-dependent effect. Moreover, Te-PC and Te-APC demonstrated stronger inhibition than PC and APC. For example, Te-PC inhibited ABTS oxidation by $28.0 \%$ at $0.0125 \mathrm{mg} \mathrm{mL}^{-1}$ and up to $97.2 \%$ at $0.1 \mathrm{mg} \mathrm{mL}^{-1}$, which were higher percentages than those of PC (23.5\% and $92.1 \%$, respectively). In previous papers, we found that both Se-PC and Se-APC performed stronger antioxidant activities than PC and APC. ${ }^{7,11,12}$ So, it was indicated in this paper that Te maintained similar antioxidant activity as $\mathrm{Se}$, and the incorporation of Te into the peptides enhanced the antioxidant activities of both phycobiliproteins. The results also demonstrated that $\mathrm{PC}$ and Te-PC had stronger inhibition than APC and Te-APC. At the concentration of $0.1 \mathrm{mg} \mathrm{mL}^{-1}$, the scavenging activity of Te-PC $(97.2 \%)$ was 2.4 times higher than that of Te-APC (39.9\%). Moreover, Te-PC and PC also showed significantly $(P<0.05)$ high inhibition on trolox (6-hydroxy-2,5,7,8-tetramethylchroman2-carboxylic acid), which was also a well-known antioxidant (data not shown).

The antioxidant activities of Te-PC and Te-APC were further confirmed by erythrocyte hemolysis assay, in which AAPH radicals could attack the erythrocyte cell membrane components, including proteins and lipids, and cause changes in the structure and function of the membranes. As shown in Figure 5C, Te-PC and Te-APC showed dose-dependent protection on erythrocytes against the AAPH-induced hemolysis. For instance, Te-PC inhibited the hemolysis by $45.6 \%$ at $0.025 \mathrm{mg} \mathrm{mL}^{-1}$ and by up to $78.6 \%$ at $0.2 \mathrm{mg} \mathrm{mL}^{-1}$, which were higher percentages than those of Te-APC $(32.2 \%$ and

Table 4 Identification of $\alpha$ and $\beta$ subunits of PC, Te-PC, APC, and Te-APC by MALDI-TOF-TOF

\begin{tabular}{|c|c|c|c|c|c|}
\hline Protein & Subunit & $\begin{array}{l}\text { Accession } \\
\text { no }\end{array}$ & $\begin{array}{l}\text { Protein } \\
\text { MW (Da) }\end{array}$ & $\begin{array}{l}\text { No of peptide } \\
\text { identified }\end{array}$ & $\begin{array}{l}\text { Protein } \\
\text { score }\end{array}$ \\
\hline \multirow[t]{2}{*}{ PC } & $\alpha$ & gi|l 8252400 & $17,588.8$ & 8 & 183 \\
\hline & $\beta$ & gi|l 8252399 & 18,082 & 10 & 191 \\
\hline \multirow[t]{2}{*}{$\mathrm{Te}^{\mathrm{P} C^{\mathrm{b}}}$} & $\alpha$ & gi| I 8252400 & $17,588.8$ & 9 & 133 \\
\hline & $\beta$ & gi|| 8252399 & 18,082 & 11 & $15 \mid$ \\
\hline \multirow[t]{2}{*}{ APC } & $\alpha$ & gi| I 633287 & I7,078.8 & 7 & 145 \\
\hline & $\beta$ & gi|29|568829 & $18,429.9$ & 10 & 163 \\
\hline \multirow[t]{2}{*}{ Te-APC } & $\alpha$ & gi|l 633287 & $17,078.8$ & 9 & 125 \\
\hline & $\beta$ & gi|29I568829 & $18,429.9$ & 11 & 171 \\
\hline
\end{tabular}

Notes: ${ }^{a}$ Results searched from NCBI non-redundant protein sequence database. ${ }^{\mathrm{b}} \mathrm{Te}-\mathrm{PC}$ and Te-APC were identified as PC and APC, respectively, since the NCBI database contains no sequence information on Te-containing proteins.

Abbreviations: PC, phycocyanin; Te-PC, tellurium-containing phycocyanin; APC, allophycocyanin; Te-APC, tellurium-containing allophycocyanin; MALDI-TOF-TOF, matrix assisted laser desorption /ionization-time of flight/time of flight; No, number; MW, molecular weight, NCBI, National Center for Biotechnology Information. 
A

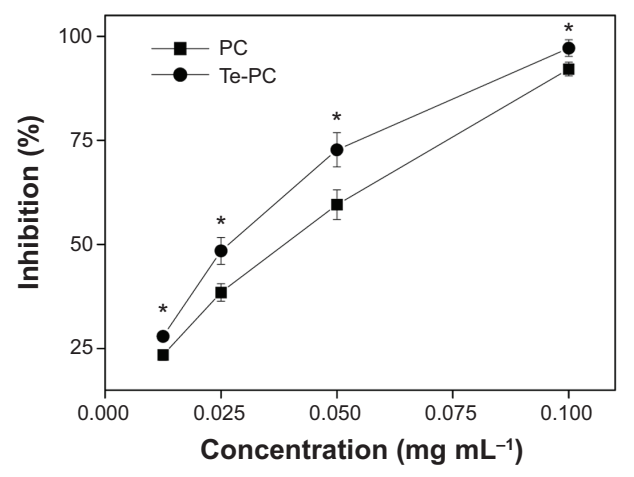

B

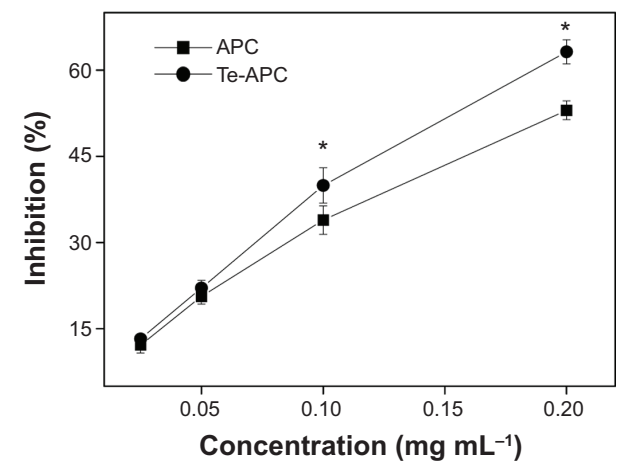

C

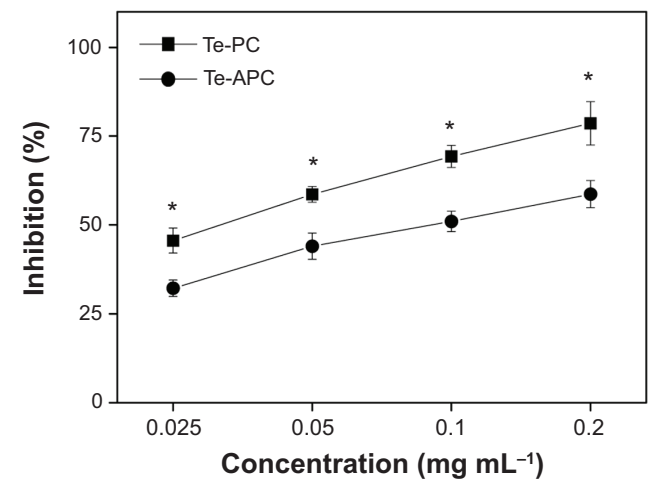

Figure 5 (A) Antioxidant activities of Te-PC and (B) Te-APC as determined by ABTS assay and (C) hemolysis assay.

Notes: Values expressed are means \pm SD of triplicates. $*$ The significant difference between the two tested groups at the same concentration is indicated at $P<0.05$.

Abbreviations: PC, phycocyanin; Te-PC, tellurium-containing phycocyanin; APC, allophycocyanin; Te-APC, tellurium-containing allophycocyanin; ABTS, 2,2'-azino-bis(3ethylbenzothiazoline-6-sulphonic acid; SD, standard deviation.

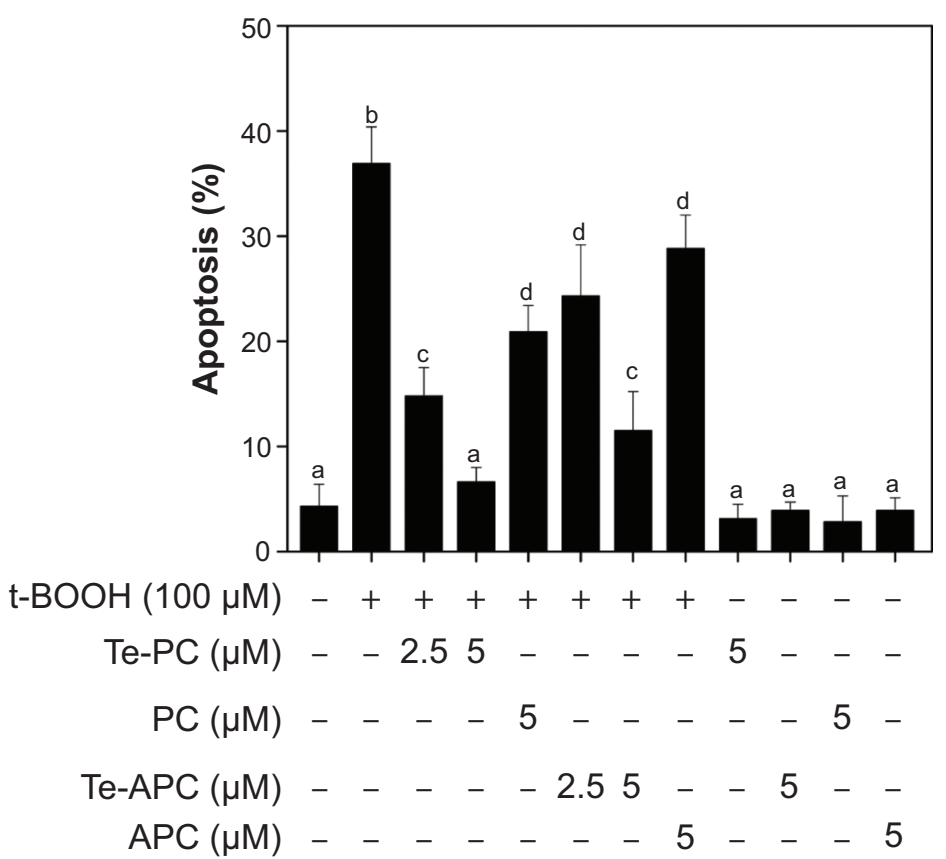

Figure 6 Te-PC, PC, Te-APC, and APC inhibit t-BOOH-induced apoptosis in HepG2 cells.

Notes: The cells were pre-incubated with different proteins for 12 hours and then co-incubated with $100 \mu \mathrm{M}$ t-BOOH for 10 hours. Cells after treatment were collected and stained with PI after fixation by $70 \%$ ethanol. Apoptotic cells with hypodiploid DNA content were measured by quantifying the sub-GI peak. Bars with different characters (a-d) are statistically different at $P<0.05$.

Abbreviations: PC, phycocyanin; Te-PC, tellurium-containing phycocyanin; APC, allophycocyanin; Te-APC, tellurium-containing allophycocyanin; t-BOOH, tert-butyl hydroperoxide; PI, propidium iodide; DNA, deoxyribonucleic acid; sub-GI, sub-gap I. 


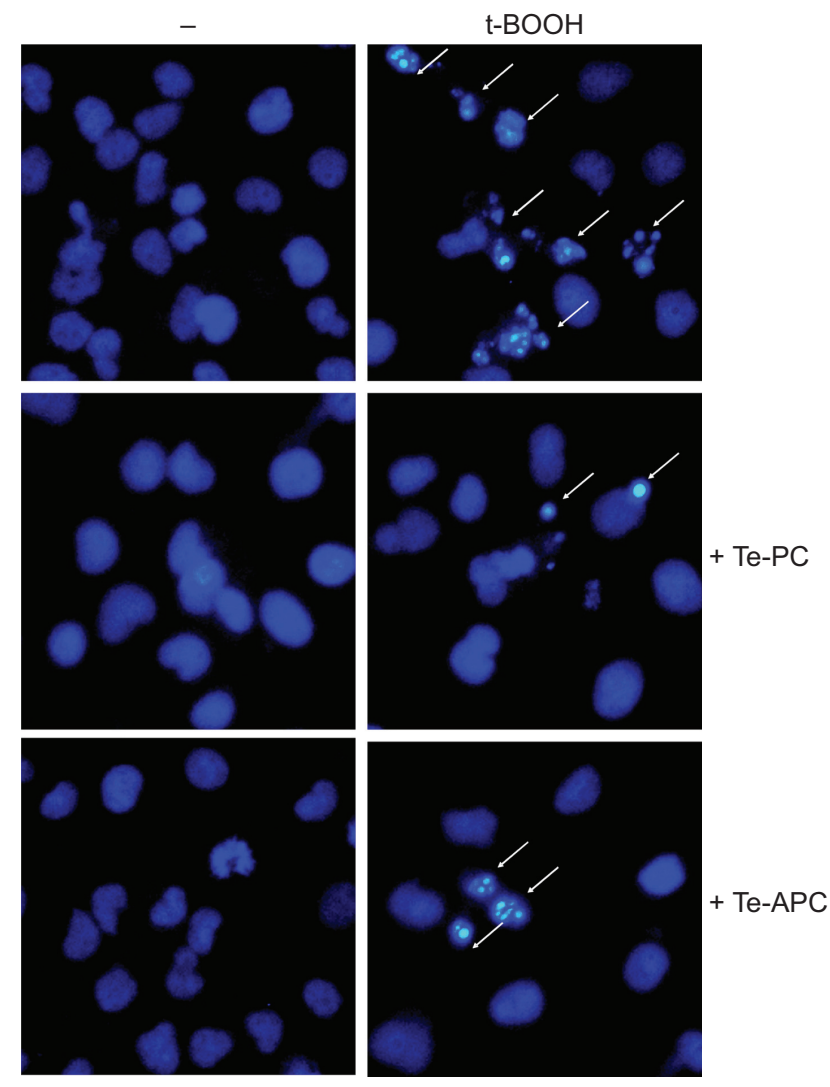

Figure 7 Te-PC and Te-APC inhibited t-BOOH-induced nuclear condensation as examined by DAPI staining assay (magnification 200X).

Notes: The cells were pre-incubated with $5 \mu \mathrm{M}$ Te-PC and Te-APC for 12 hours and co-incubated with $100 \mu \mathrm{M}$ t-BOOH for 10 hours. The images shown here are representative of three independent experiments with similar results. White arrows represent nuclear condensation.

Abbreviations: Te-PC, tellurium-containing phycocyanin; Te-APC, telluriumcontaining allophycocyanin; t-BOOH, tert-butyl hydroperoxide; DAPI, 4',6-diamidino2-phenylindole; -, no drugs added.

$58.7 \%$ at the same concentrations). The difference in antioxidant activities of Te-PC and Te-APC obtained by this assay was quite consistent with those obtained by ABTS, DPPH (2,2-diphenyl-1-picryl-hydrazyl), and superoxide anion scavenging assays.

Taken together, and in comparison with PC and APC, the incorporation of Te into proteins significantly enhances their antioxidant activities. This observation is consistent with those of Se-PC and Se-APC, in which the increased antioxidant activities were due to the incorporation of Se into the protein as seleno-amino acids. ${ }^{7}$ Possibly, Te was incorporated into Te-PC and Te-APC in organic forms like Te-amino acids. Previous studies have demonstrated the antioxidative properties of organotellurium compounds in cell systems. ${ }^{24,25}$ Therefore, considering the biological similarity between Se and Te and the comparison of the antioxidant activities, we concluded that the incorporation of organic Te into PC and APC accounts for the enhanced antioxidant activities.

\section{Te-PC and Te-APC attenuate tert-butyl hydroperoxide-induced apoptosis in HepG2 cells}

The livers in humans and animals are particularly susceptible to toxic and oxidative insults, because the portal vein brings blood to this organ after intestinal absorption. The absorbed drugs and xenobiotics in a concentrated form can cause overproduction of reactive oxygen species (ROS) and other free radicals, which could result in inflammatory and fibrotic processes. ${ }^{11}$ Our previous studies ${ }^{11}$ have established a hepatoprotective model by using the HepG2 cell line as a cell model and with tert-butyl hydroperoxide (t-BOOH) as an oxidation agent. The cytotoxicity of t-BOOH toward HepG2 cells was mainly attributed to the induction of ROS-mediated apoptosis. ${ }^{11}$ Therefore, in the present study, this model was used to examine the in vitro antioxidant activities and hepatoprotective effects against free radicals. The cytotoxic effects of $\mathrm{t}-\mathrm{BOOH}$ and the protective effects of Te-PC, PC, Te-APC, and APC on HepG2 cells were first examined by DNA flow cytometric analysis. As shown in Figure 6, exposure of cells to $100 \mu \mathrm{M}$ $\mathrm{t}-\mathrm{BOOH}$ resulted in a marked increase in the proportion of apoptotic cells, as reflected by the increase in sub-G1 peaks from $4.3 \%$ (control) to $36.9 \%$. However, pretreatment of the cells with 2.5 and $5 \mu \mathrm{M}$ Te-PC and Te-APC, respectively, significantly blocked the t-BOOH-induced apoptosis. Their protective effects were significantly higher than those of PC and APC at $5 \mu \mathrm{M}$. These results demonstrated that Te incorporation significantly enhanced the hepatoprotective effects against free radicals. Moreover, we showed that $5 \mu \mathrm{M} \mathrm{Te}-\mathrm{PC}$, PC, Te-APC, and APC alone did not cause an increase in apoptotic sub-G1 peak, indicating that these proteins are non-toxic to the cells under the effective protection concentrations.

The protective effects of Te-PC and Te-APC on HepG2 cells against t-BOOH-induced apoptosis were further characterized by DAPI staining assay. After the exposure to $100 \mu \mathrm{M}$ t-BOOH, HepG2 cells exhibited typical apoptotic features, such as chromatin condensation and condensed nuclear fragments, as indicated by the arrows in Figure 7. However, co-treatment of the cells with Te-PC and Te-APC effectively prevented the $\mathrm{t}-\mathrm{BOOH}$-induced morphological alterations, while cells exposed to Te-PC and Te-APC alone showed normal nuclei of oval shape, which clearly demonstrates that Te-PC and Te-APC block t-BOOH-induced apoptosis in HepG2 cells.

\section{Conclusion}

In summary, we purified Te-PC and Te-APC from Te-enriched $S$. platensis by a fast, simple, efficient liquid 
chromatographic method. Te was incorporated into PC and APC, as identified by MALDI-TOF-TOF analysis. Most importantly, Te incorporation enhanced the antioxidant and hepatoprotective activities of both phycobiliproteins. For future applications, the Te-containing proteins inside human bodies could be digested by different enzymes, such as pep$\sin$, trypsin, and $\alpha$-chymotrypsin. The enzymatic digestion could cause the active peptides and amino acids to become exposed to the environment, and thus enhance their biological activities. Therefore, Te-PC and Te-APC are novel organic Te species with application potential in antioxidation, and deserve further development for treatment of diseases related to oxidative stress in the future.

\section{Acknowledgments}

This work was supported by National Science and Technology support program (2012BAD18B01), Natural Science Foundation of China and Guangdong Province, Program for New Century Excellent Talents in University, Research Fund for the Doctoral Program of Higher Education of China, the Fundamental Research Funds for the Central Universities and China Postdoctoral Science Foundation.

\section{Disclosure}

The authors declare that there are no conflicts of interest in this work.

\section{References}

1. Deng R, Chow TJ. Hypolipidemic, antioxidant, and antiinflammatory activities of microalgae Spirulina. Cardiovasc Ther. 2010;28(4):e33-e45.

2. Kulshreshtha A, Zacharia AJ, Jarouliya U, Bhadauriya P, Prasad GB, Bisen PS. Spirulina in health care management. Curr Pharm Biotechnol. 2008;9(5):400-405.

3. Pabon MM, Jernberg JN, Morganti J, et al. A spirulina-enhanced diet provides neuroprotection in an $\alpha$-synuclein model of Parkinson's disease. PLoS One. 2012;7(9):e45256.

4. Karkos PD, Leong SC, Karkos CD, Sivaji N, Assimakopoulos DA. Spirulina in clinical practice: evidence-based human applications. Evid Based Complement Alternat Med. 2011;2011:531053.

5. Chen T, Zheng W, Wong YS, Yang F, Bai Y. Accumulation of selenium in mixotrophic culture of Spirulina platensis on glucose. Bioresour Technol. 2006;97(18):2260-2265.

6. Li ZY, Guo SY, Li L. Bioeffects of selenite on the growth of Spirulina platensis and its biotransformation. Bioresour Technol. 2003;89(2):171-176.

7. Chen $\mathrm{T}$, Wong YS. In vitro antioxidant and antiproliferative activities of selenium-containing phycocyanin from selenium-enriched Spirulina platensis. J Agric Food Chem. 2008;56(12):4352-4358.

8. Chen T, Wong YS, Zheng WJ. Purification and characterization of selenium-containing phycocyanin from selenium-enriched Spirulina platensis. Phytochemistry. 2006;67(22):2424-2430.

9. Encinar JR, Ouerdane L, Buchmann W, Tortajada J, Lobinski R, Szpunar J. Identification of water-soluble selenium-containing proteins in selenized yeast by size-exclusion-reversed-phase HPLC/ICPMS followed by MALDI-TOF and electrospray Q-TOF mass spectrometry. Anal Chem. 2003;75(15):3765-3774.
10. Behne D, Kyriakopoulos A. Mammalian selenium-containing proteins. Annu Rev Nutr. 2001;21(1):453-473.

11. Fan CD, Jiang J, Yin X, Wong KH, Zheng W, Chen T. Purification of selenium-containing allophycocyanin from selenium-enriched Spirulina platensis and its hepatoprotective effect against t-BOOH-induced apoptosis. Food Chem. 2012;134(1):253-261.

12. Zhang H, Chen T, Jiang J, Wong YS, Yang F, Zheng W. Seleniumcontaining allophycocyanin purified from selenium-enriched Spirulina platensis attenuates AAPH-induced oxidative stress in human erythrocytes through inhibition of ROS generation. J Agric Food Chem. 2011;59(16):8683-8690.

13. Chasteen TG, Bentley R. Biomethylation of selenium and tellurium: microorganisms and plants. Chem Rev. 2003;103(1):1-25.

14. Franzle S, Markert B. The Biological System of the Elements (BSE). Part II: a theoretical model for establishing the essentiality of chemical elements. The application of stoichiometric network analysis to the biological system of the elements. Sci Total Environ. 2000;249(1-3):223-241.

15. Rayman MP. The importance of selenium to human health. Lancet. 2000;356(9225):233-241

16. Chasteen TG, Fuentes DE, Tantaleán JC, Vásquez CC. Tellurite: history, oxidative stress, and molecular mechanisms of resistance. FEMS Microbiol Rev. 2009;33(4):820-832.

17. Sredni B. Immunomodulating tellurium compounds as anti-cancer agents. Semin Cancer Biol. 2012;22(1):60-69.

18. Morell P, Toews AD. Schwann cells as targets for neurotoxicants. Neurotoxicology. 1996;17(3-4):685-695.

19. Morell P, Toews AD, Wagner M, Goodrum JF. Gene expression during tellurium-induced primary demyelination. Neurotoxicology. 1994; 15(1):171-180.

20. Widy-Tyszkiewicz E, Piechal A, Gajkowska B, Smialek M. Telluriuminduced cognitive deficits in rats are related to neuropathological changes in the central nervous system. Toxicol Lett. 2002;131(3): 203-214.

21. Santos DB, Schiar VP, Paixão MW, et al. Hemolytic and genotoxic evaluation of organochalcogens in human blood cells in vitro. Toxicol In Vitro. 2009;23(6):1195-1204.

22. Roy S, Hardej D. Tellurium tetrachloride and diphenyl ditelluride cause cytotoxicity in rat hippocampal astrocytes. Food Chem Toxicol. 2011; 49(10):2564-2574.

23. Tiekink ER. Therapeutic potential of selenium and tellurium compounds: opportunities yet unrealised. Dalton Trans. 2012;41(21): 6390-6395.

24. Ba LA, Döring M, Jamier V, Jacob C. Tellurium: an element with great biological potency and potential. Org Biomol Chem. 2010;8(19): 4203-4216.

25. Wieslander E, Engman L, Svensjö E, et al. Antioxidative properties of organotellurium compounds in cell systems. Biochem Pharmacol. 1998;55(5):573-584.

26. Salerno Pimentel IA, Paladi Cde S, Katz S, de Souza Júdice WA, Cunha RL, Barbiéri CL. In vitro and in vivo activity of an organic tellurium compound on Leishmania (Leishmania) chagasi. PLoS One. 2012;7(11):e48780.

27. Vij P, Hardej D. Evaluation of tellurium toxicity in transformed and non-transformed human colon cells. Environ Toxicol Pharmacol. 2012;34(3):768-782.

28. Abondanza TS, Oliveira CR, Barbosa CM, et al. Bcl-2 expression and apoptosis induction in human HL60 leukaemic cells treated with a novel organotellurium(IV) compound RT-04. Food Chem Toxicol. 2008;46(7):2540-2545.

29. Cunha RL, Urano ME, Chagas JR, et al. Tellurium-based cysteine protease inhibitors: evaluation of novel organotellurium(IV) compounds as inhibitors of human cathepsin B. Bioorg Med Chem Lett. 2005;15(3):755-760.

30. Persike DS, Cunha RL, Juliano L, et al. Protective effect of the organotelluroxetane RF-07 in pilocarpine-induced status epilepticus. Neurobiol Dis. 2008;31(1):120-126. 
31. Patil G, Chethana S, Madhusudhan MC, Raghavarao KS. Fractionation and purification of the phycobiliproteins from Spirulina platensis. Bioresour Technol. 2008;99(15):7393-7396.

32. Reddy MC, Subhashini J, Mahipal SV, et al. C-Phycocyanin, a selective cyclooxygenase-2 inhibitor, induces apoptosis in lipopolysaccharidestimulated RAW 264.7 macrophages. Biochem Biophys Res Commun. 2003;304(2):385-392.

33. Romay C, Armesto J, Remirez D, González R, Ledon N, García I. Antioxidant and anti-inflammatory properties of C-phycocyanin from blue-green algae. Inflamm Res. 1998;47(1):36-41.

34. Yeh SW, Ong LJ, Clark JH, Glazer AN. Fluorescence properties of allophycocyanin and a crosslinked allophycocyanin trimer. Cytometry. 1987;8(1):91-95.

35. Zhang YM, Chen F. A simple method for efficient separation and purification of c-phycocyanin and allophycocyanin from Spirulina platensis. Biotechnol Tech. 1999;13(9):601-603.

36. Chen TF, Wong YS. Selenocystine induces caspase-independent apoptosis in MCF-7 human breast carcinoma cells with involvement of p53 phosphorylation and reactive oxygen species generation. Int $J$ Biochem Cell Biol. 2009;41(3):666-676.
37. Chaiklahan R, Chirasuwan N, Loha V, Tia S, Bunnag B. Separation and purification of phycocyanin from Spirulina sp. using a membrane process. Bioresour Technol. 2011;102(14):7159-7164.

38. Benedetti S, Rinalducci S, Benvenuti F, et al. Purification and characterization of phycocyanin from the blue-green alga Aphanizomenon flos-aquae. J Chromatogr B Analyt Technol Biomed Life Sci. 2006;833(1):12-18.

39. Bermejo R, Talavera EM, Alvarez-Pez JM. Chromatographic purification and characterization of B-phycoerythrin from Porphyridium cruentum. Semipreparative high-performance liquid chromatographic separation and characterization of its subunits. J Chromatogr A. 2001;917(1-2):135-145.

40. Minkova K, Tchorbadjieva M, Tchernov A, Stojanova M, Gigova L, Busheva M. Improved procedure for separation and purification of Arthronema africanum phycobiliproteins. Biotechnol Lett. 2007;29(4): 647-651.

41. Zhang Y, Chen X, Zhou B, et al. A new model of phycobilisome in Spirulina platensis. Sci China C Life Sci. 1999;42(1):74-79.

42. Leong LP, Shui G. An investigation of antioxidant capacity of fruits in Singapore markets. Food Chem. 2002;76(1):69-75.
Drug Design, Development and Therapy

\section{Publish your work in this journal}

Drug Design, Development and Therapy is an international, peerreviewed open-access journal that spans the spectrum of drug design and development through to clinical applications. Clinical outcomes, patient safety, and programs for the development and effective, safe, and sustained use of medicines are a feature of the journal, which

\section{Dovepress}

has also been accepted for indexing on PubMed Central. The manuscript management system is completely online and includes a very quick and fair peer-review system, which is all easy to use. Visit http://www.dovepress.com/testimonials.php to read real quotes from published authors.

Submit your manuscript here: http://www.dovepress.com/drug-design-development-and-therapy-journal 